\title{
Amino acid availability regulates p70 S6 kinase and multiple translation factors
}

\author{
Xuemin WANG*, Linda E. CAMPBELL*, Christa M. MILLER $†$ and Christopher G. PROUD*1 \\ *Department of Anatomy and Physiology, University of Dundee, Dundee DD1 4HN, U.K., and †Department of Biosciences, University of Kent at Canterbury, \\ Canterbury CT2 7NJ, U.K.
}

\begin{abstract}
Incubation of Chinese hamster ovary cells without amino acids for up to 60 min caused a rapid marked decrease in p70 S6 kinase activity and increased binding of initiation factor eIF4E to its inhibitory regulator protein $4 \mathrm{E}-\mathrm{BP} 1$. This was associated with dephosphorylation of 4E-BP1 and eIF4E and dissociation of eIF4E from eIF4G. All these effects were rapidly reversed by resupplying a mixture of amino acids and this was blocked by rapamycin and by inhibitors of phosphatidylinositol 3-kinase, implying a role for phosphatidylinositol 3-kinase in the signalling pathway linking amino acids with the control of p70 S6 kinase activity and the phosphorylation of these translation factors. Amino acid withdrawal also led to changes in the phospho-
\end{abstract}

rylation of other translation factors; phosphorylation of eIF4E decreased whereas elongation factor eEF2 became more heavily phosphorylated, each of these changes being associated with decreased activity of the factor in question. Earlier studies have suggested that protein kinase B (PKB) may act upstream of p70 S6 kinase. However, amino acids did not affect the activity of PKB, indicating that amino acids activate p70 S6 kinase through a pathway independent of this enzyme. Studies with individual amino acids suggested that the effects on p70 S6 kinase activity and translation-factor phosphorylation were independent of cell swelling. The data show that amino acid supply regulates multiple translation factors in mammalian cells.

\section{INTRODUCTION}

Amino acid deficiency results in decreased rates of protein synthesis in eukaryotic cells. One of the changes in the translational machinery which can be induced by amino acid deprivation is the increased phosphorylation of the $\alpha$-subunit of initiation factor-2 (eIF $2 \alpha$; eIF denotes eukaryotic initiation factor), resulting in inhibition of the activity of the guanine nucleotide-exchange factor, eIF2B, which is required to recycle eIF2 and maintain high rates of translation initiation (reviewed in [1-3]). This regulatory system has been most intensively studied in yeast, which possess an eIF2 $\alpha$ kinase, GCN2 (GCN, general control, non-depressible), which is activated under conditions of amino acid deficiency [4,5]. A GCN2 homologue has recently been identified in Drosophila [6], although no such enzyme has yet been reported from mammalian cells.

Other signalling pathways can also acutely regulate mRNA translation in mammalian cells by affecting the states of phosphorylation and the activities of other translation factors or regulatory proteins $[2,7,8]$. One such pathway is the rapamycin-sensitive signalling pathway, which is activated by certain hormones, growth factors and other mitogens, and is believed to lead to the stimulation of a variety of regulatory steps in mRNA translation. This pathway is also termed the FRAP/mTOR (FK506-binding protein-rapamycin-associated protein $/ \mathrm{mam}$ malian target of rapamycin) pathway, referring to the protein that is the target of rapamycin action. It is linked: (i) to the regulation of the cap-binding translation factor, eIF4E, through the regulatory proteins known as $4 \mathrm{E}$-binding proteins (4E-BPs) or $\mathrm{pH}$ - and acid-stable (PHAS) proteins (reviewed in [9]); (ii) to activation of p70 S6 kinase (the $70 \mathrm{kDa}$ protein kinase acting on ribosomal protein S6) [10], and hence the phosphorylation of ribosomal protein S6, and, as suggested by recent data [11-13], to the upregulation of the translation of mRNAs with $5^{\prime}$ terminal polypyrimidine tracts (5'-TOP mRNAs); and (iii) to the regulation of the phosphorylation of elongation factor eEF2 and the control of elongation [14].

Here we demonstrate that amino acid availability regulates this rapamycin-sensitive signalling pathway. Amino acid deficiency results in the reversible inactivation of p70 S6 kinase. This is associated with increased binding of the inhibitory protein 4EBP1 to eIF4E, and dissociation of the eIF4F complex, containing eIF4G, which is involved in cap-dependent translation initiation. Amino acid deprivation also brought about decreased phosphorylation of eIF4E and increased phosphorylation of eukaryotic elongation factor eEF2. These data highlight new mechanisms by which amino acid availability can regulate several translation factors in mammalian cells.

\section{MATERIALS AND METHODS}

\section{Chemicals and biochemicals}

$\mathrm{m}^{7}$ GTP (7-methylGTP)-Sepharose was from Pharmacia Biotech. $\gamma-{ }^{32} \mathrm{P}$-labelled ATP, $\left[{ }^{32} \mathrm{P}\right] \mathrm{P}_{\mathrm{i}}$ and ${ }^{35} \mathrm{~S}$-labelled methionine/cysteine were purchased from Amersham. Materials for tissue culture were obtained from Gibco. Microcystin-LR and rapamycin were from Calbiochem. The antiserum to rodent eIF4E has been

Abbreviations used: $\mathrm{CHO}$, Chinese hamster ovary; eEF, eukaryotic elongation factor; elF, eukaryotic initiation factor; elF2 $\alpha$, $\alpha$-subunit of initiation factor-2; 4E-BP1, eukaryotic initiation factor elF4E-binding protein-1; FRAP, FK506-binding protein-rapamycin-associated protein; GCN, general control, non-depressible (GCN2 is a protein kinase acting on elF2 $\alpha$ ); JNK, c-Jun N-terminal kinase; MAP, mitogen-activated protein; $m^{7}$ GTP, 7 methylGTP; Mnk1, MAP kinase signal-integrating kinase-1; mTOR, mammalian target of rapamycin; p70 S6 kinase, 70 kDa protein kinase acting on ribosomal protein S6; PDK1, phosphoinositide-dependent kinase-1; PI 3-kinase, phosphatidylinositol 3-kinase; PKB, protein kinase B; 5'-TOP, 5'terminal tract of polypyrimidines.

1 To whom correspondence should be addressed (e-mail CGPROUD@ bad.dundee.ac.uk) 
described previously [15] and that to 4E-BP1 was raised against a synthetic peptide corresponding to residues 101-113 of the human protein. The antisera recognizing eIF4G and phosphorylated eIF $2 \alpha$ were kindly provided by Dr. S. Morley (University of Sussex, Brighton, U.K.) and Dr. G. Krause (Wayne State University, Detroit, MI, U.S.A.) [16], respectively. Antisera to individual isoforms of protein kinase $\mathrm{B}(\mathrm{PKB})$ were generously provided by K. Walker and Dr. D. R. Alessi (University of Dundee, Dundee, U.K.) [17].

\section{Cell culture and treatment}

Chinese hamster ovary (CHO.K1) cells were kindly provided by Dr. L. Ellis (Houston, TX, U.S.A.), were maintained as described previously [18] and were incubated without serum for $18 \mathrm{~h}$ prior to use. To deprive the cells of amino acids, cells were transferred to Earle's balanced salt solution (Gibco-BRL). To restore amino acids, an appropriate volume of a $10 \times$ stock of amino acids (dissolved in Earle's balanced salt solution) was added. This stock contained tryptophan $(0.6 \mathrm{mM})$, methionine $(2 \mathrm{mM})$, histidine $(2.5 \mathrm{mM})$, tyrosine, cysteine and phenylalanine (all at $4 \mathrm{mM})$, arginine $(5 \mathrm{mM})$, lysine $(10 \mathrm{mM})$, threonine and the branched-chain amino acids valine, isoleucine and leucine (each at $8 \mathrm{mM})$, and glutamic acid $(40 \mathrm{mM})$.

\section{Assays for protein kinases, translation-factor phosphorylation and association}

The activity of p70 S6 kinase was measured after immunoprecipitation using anti-(p70 S6 kinase) antibodies against a peptide substrate as described previously [19]. PKB was assayed (after immunoprecipitation with a mixture of antisera recognizing all three isoforms of PKB [17]) using a synthetic peptide substrate as described earlier [20]. The activities of p38 MAP (mitogenactivated protein) kinase and c-Jun N-terminal kinase (JNK) were assayed using heat shock protein 25 or a fusion protein (glutathione S-transferase-c-Jun) as described previously [21,22]. MAP kinase activity was assessed by analysis of cell extracts in Western blots using a commercial antibody (New England Biolabs), which specifically recognizes the active phosphorylated form of MAP kinase (both isoforms).

In order to assess the state of phosphorylation of 4E-BP1 by radiolabelling, cells were preincubated with $\left[{ }^{32} \mathrm{P}\right] \mathrm{P}_{\mathrm{i}}$ for $150 \mathrm{~min}$ in medium free of phosphate, and were then subjected to appropriate treatments. This was followed by extraction of the cells in standard extraction buffer and immunoprecipitation of the 4E-BP1 [23], which was analysed by SDS/PAGE and autoradiography.

eIF4E and associated proteins were isolated from cell extracts by affinity chromatography on $\mathrm{m}^{7} \mathrm{GTP}-$ Sepharose and subjected to SDS/PAGE and Western blotting as described previously $[23,24]$ (any minor modifications are noted in the text). For analysis of eIF4G, samples were run on an $8 \%$ polyacrylamide gel and blots were developed with anti-eIF4G antiserum. eIF2 $\alpha$ phosphorylation was assessed by Western blotting using an antibody to the phosphorylated form of the protein (to ascertain the level of the phosphoprotein; [16]), which was then compared with the total level of eIF $2 \alpha$ in each sample, assessed using a monoclonal antibody against eIF $2 \alpha$ (a kind gift from the late Dr. E. Henshaw, Rochester, NY, U.S.A.). The states of phosphorylation of eIF4E and of eEF2 were assessed by isoelectric focusing/immunoblotting as described previously [14,25,26]. Immunoblots were developed by enhanced chemiluminescence.

\section{RESULTS}

Amino acid supply regulates the p70 S6 kinase

Removal of amino acids from confluent $\mathrm{CHO}$ cells resulted in rapid inactivation of p70 S6 kinase, and this was reversed by resupplying amino acids (Table 1a). The activation of p70 S6 kinase induced by restoring amino acids was completely blocked by the immunosuppressant rapamycin (used at $25 \mathrm{nM}$ ) and by either of two selective inhibitors of phosphatidylinositol 3-kinase (PI 3-kinase), LY294002 (used at $30 \mu \mathrm{M}$ ) and wortmannin (used at $100 \mathrm{nM}$; Table 1b). This is in line with data for its regulation by other stimuli: rapamycin blocks p70 S6 kinase activation in response to all agonists so far tested (for review, see [10]), and PI 3-kinase appears to be required for its activation by a wide range of stimuli, but not by all of them [28-34]. Rapamycin and wortmannin each repressed the basal activity of p70 S6 kinase in serum-starved cells: cells were incubated for $60 \mathrm{~min}$ in serum-free medium in the presence of rapamycin or wortmannin at the standard concentrations. In rapamycin-treated cells p70 S6 kinase activity was $26 \pm 4.5 \%(n=6)$ of the serum-starved control, whereas after wortmannin treatment the value was $24.8 \pm 5.9 \%$ $(n=4)$, each being very similar to the $23 \%$ residual activity seen after 60 min of amino acid withdrawal (Table 1a).

\section{Table 1 Amino acid supply regulates p70 S6 kinase}

(a) CHO.K1 cells were untreated (control), deprived of amino acids for the indicated times or deprived of amino acids for 60 min followed by incubation in medium containing the complete amino acid mixture for the times shown. Extracts were subjected to immunoprecipitation with anti-(p70 S6 kinase) antiserum and the immunoprecipitates were assayed for p70 S6 kinase activity (see the Materials and methods section). (b) $\mathrm{CHO}$.K1 cells were untreated or deprived of amino acids for 45 min followed, where indicated, by incubation in the presence of the full amino acid mixture with further additions of wortmannin (100 nM), LY294002 $(30 \mu \mathrm{M})$ or rapamycin $(25 \mu \mathrm{M})$.

(a) Time course of removal or resupply of amino acids

\begin{tabular}{|c|c|}
\hline Condition/time & $\begin{array}{l}\text { p70 S6 kinase } \\
\text { activity (\% of control } \\
\pm \text { S.E.M.; } n=3)\end{array}$ \\
\hline Control (serum-starved) & 100 \\
\hline \multicolumn{2}{|l|}{ Amino acid withdrawal } \\
\hline $5 \min$ & $75.7 \pm 3.4$ \\
\hline $15 \mathrm{~min}$ & $61.3 \pm 1.1$ \\
\hline $30 \mathrm{~min}$ & $47.2 \pm 3.4$ \\
\hline $45 \mathrm{~min}$ & $36.8 \pm 1.2$ \\
\hline $60 \min$ & $23.0 \pm 1.5$ \\
\hline \multicolumn{2}{|l|}{ Amino acid resupply } \\
\hline $5 \min$ & $69.1 \pm 3.5$ \\
\hline $15 \min$ & $110.0 \pm 8.0$ \\
\hline $30 \mathrm{~min}$ & $105.9 \pm 9.2$ \\
\hline \multicolumn{2}{|c|}{ (b) Effects of inhibitors on re-activation upon resupply of amino acids } \\
\hline Condition & $\begin{array}{l}\text { p70 S6 kinase } \\
\text { activity }(\% \text { of control } \\
\pm \text { S.E.M. } ; n=3)\end{array}$ \\
\hline Control (serum-starved) & 100 \\
\hline Amino acid withdrawal & $41.5 \pm 4.5$ \\
\hline Amino acids resupplied & $126.2 \pm 20.0$ \\
\hline+ wortmannin & $41.9 \pm 6.4$ \\
\hline + LY294002 & $43.0 \pm 7.1$ \\
\hline + rapamycin & $40.4 \pm 3.9$ \\
\hline
\end{tabular}


A

\begin{tabular}{|llllll|}
\hline 1 & 2 & 3 & 4 & 5 & 6 \\
\hline & & & & & \\
\hline & & & & \\
\hline
\end{tabular}

B

\begin{tabular}{|llllll|}
\hline 1 & 2 & 3 & 4 & 5 & 6 \\
\hline & & & & & \\
\hline & & & & & \\
\hline
\end{tabular}

Figure 1 Amino acid withdrawal does not induce activation of p38 MAP kinase or JNK

Serum-starved CHO.K1 cells were extracted without further treatment (lanes 2 and 3), pretreated with $0.25 \mathrm{mM}$ sodium arsenite for $20 \mathrm{~min}$ (lane 1) or subjected to amino acid withdrawal for 30 or $60 \mathrm{~min}$ (lanes 4 and 5) followed by resupply of amino acids for 30 min (lane 6) prior to extraction. Samples were then analysed for p38 MAP kinase activity (using heat-shock protein 25 [hsp25] as substrate [21], A) or JNK (using a glutathione S-transferase (GST)-c-Jun fusion protein as substrate [22], B). Samples were analysed by SDS/PAGE and autoradiography and the Figure shows the resulting autoradiograph with the positions of the substrate proteins indicated.

\section{Table 2 Amino acid supply does not affect the activity of PKB}

PKB was measured as described in the Materials and methods section (using a peptide substrate after immunoprecipitation). CHO.K1 cells were either serum-starved or transferred to Earle's balanced salt solution (EBSS) for $60 \mathrm{~min}$ and, in some cases, resupplied with amino acids for the times indicated. As a positive control for the activation of PKB, some serum-starved cells were stimulated with serum $(20 \%, v / v)$ for $30 \mathrm{~min}$.

\begin{tabular}{ll}
\hline Condition/time & $\begin{array}{l}\text { PKB activity (\% of control } \\
\pm \text { S.E.M.; } n=3)\end{array}$ \\
\hline Control (serum-starved) & 100 \\
EBSS, 60 min & $80.7 \pm 11.6$ \\
$\quad+$ amino acids for 5 min & $59.3 \pm 4.8$ \\
$\quad+$ amino acids for 10 min & $62.0 \pm 6.4$ \\
$\quad+$ amino acids for 20 min & $63.2 \pm 7.3$ \\
Serum-starved plus serum & $435 \pm 41.2$ \\
\hline
\end{tabular}

Amino acid withdrawal did not result in stimulation of the activities of the stress-activated kinases, p38 MAP kinase or JNK (Figure 1). If anything, a slight reduction was seen, although since the basal activity was extremely low compared with that elicited by treatment of the cells with arsenite, this change in activity was very small indeed. Amino acid withdrawal had no effect on the activity of ERK (the classical MAP kinase; results not shown). It does not, therefore, elicit a stress response in terms of activation of the stress-activated-kinase cascades over the time period studied here, and does not affect the signalling pathways upstream of the eIF4E kinase, MAP kinase signal-integrating kinase-1 (Mnk1; p38 MAP kinase or ERK [35]).

$\mathrm{PKB}$ has been reported to lie upstream of p70 S6 kinase $[36,37]$. Since it is regulated in a PI 3-kinase-dependent manner, it has been suggested that it may provide a link between PI 3kinase and the activation of p70 S6 kinase. We therefore assessed whether amino acids affect PKB activity in parallel with the activation of p70 S6 kinase activity. Removal of amino acids did cause a small fall in PKB activity (much less than the change in p70 S6 kinase activity), but there was no increase in PKB activity when amino acids were added back, although marked activation was seen when CHO.K1 cells were stimulated with serum (Table 2).

\section{Amino acid deficiency leads to increased binding of 4E-BP1 to elF4E}

The signalling pathway that regulates p 70 S6 kinase also regulates the phosphorylation of 4E-BP1 (reviewed in [9]), although there appears to be a bifurcation in the pathway upstream of p70 S6 kinase and 4E-BP1 [38]. As shown in Figure 2(A), depriving cells of all amino acids caused a rapid and marked increase in the amount of 4E-BP1 recovered with eIF4E when cell extracts were subjected to affinity chromatography on $\mathrm{m}^{7} \mathrm{GTP}$ Sepharose. This increase in 4E-BP1 binding was accompanied by a decrease in the amount of eIF4G bound to eIF4E (Figure 2B), as expected from the competitive nature of the interactions of 4E-BP1 and eIF4G with eIF4E $[39,40]$. The increased binding of 4E-BP1 to eIF4E appeared to be due, again as expected, to a decrease in its overall level of phosphorylation, as judged by its increased mobility on SDS/PAGE (Figure 2C). To confirm this, the phosphorylation state of 4E-BP1 was assessed by radiolabelling. As shown in Figure 3, incubation of cells in mixture lacking amino acids resulted in decreased labelling of 4E-BP1. This was reversed rapidly by addition of the amino acid mixture to the cells. (Only two bands are visible on the autoradiograph, as opposed to three on SDS/PAGE, presumably because the fastest-migrating one was not phosphorylated: this is similar to earlier data from fat cells [23].) Thus the changes in phosphorylation status of 4E-BP1 inferred from its mobility on SDS/PAGE are borne out by examination by radiolabelling in intact cells.

Resupplying the cells with amino acids resulted in a rapid release of 4E-BP1 from eIF4E, and this was linked to increased phosphorylation of 4E-BP1 and formation of eIF4E-4G complexes (Figures $2 \mathrm{~A}-2 \mathrm{C}$ ). When tested across a range of dilutions of the amino acid mixture, a 4-fold lower concentration of amino acids caused substantial phosphorylation of 4E-BP1 and the effect was essentially complete at half the standard concentration (Figure 2D). Corresponding changes in the association of eIF4E with 4E-BP1 and eIF4G were observed (results not shown). Rapamycin and inhibitors of PI 3-kinase blocked the ability of amino acids to induce release of 4E-BP1 from eIF4E and the binding of eIF4G to eIF4E (Figures 2E-2G).

\section{Amino acid supply regulates the phosphorylation of certain other translation factors}

eIF4E phosphorylation was assessed by isoelectric focusing/ Western blotting. Amino acid depletion caused a modest but reproducible decrease (typically from $30 \%$ in control cells to $15 \%$ without amino acids; four separate experiments) in the phosphorylation of eIF4E, as manifested by an increase in the intensity of the lower band (non-phosphorylated eIF4E) relative to the upper band (phosphorylated eIF4E). This effect was rapidly reversed by resupplying amino acids (Figure 4A). Since the association of eIF4E with 4E-BP1 blocks the phos- 

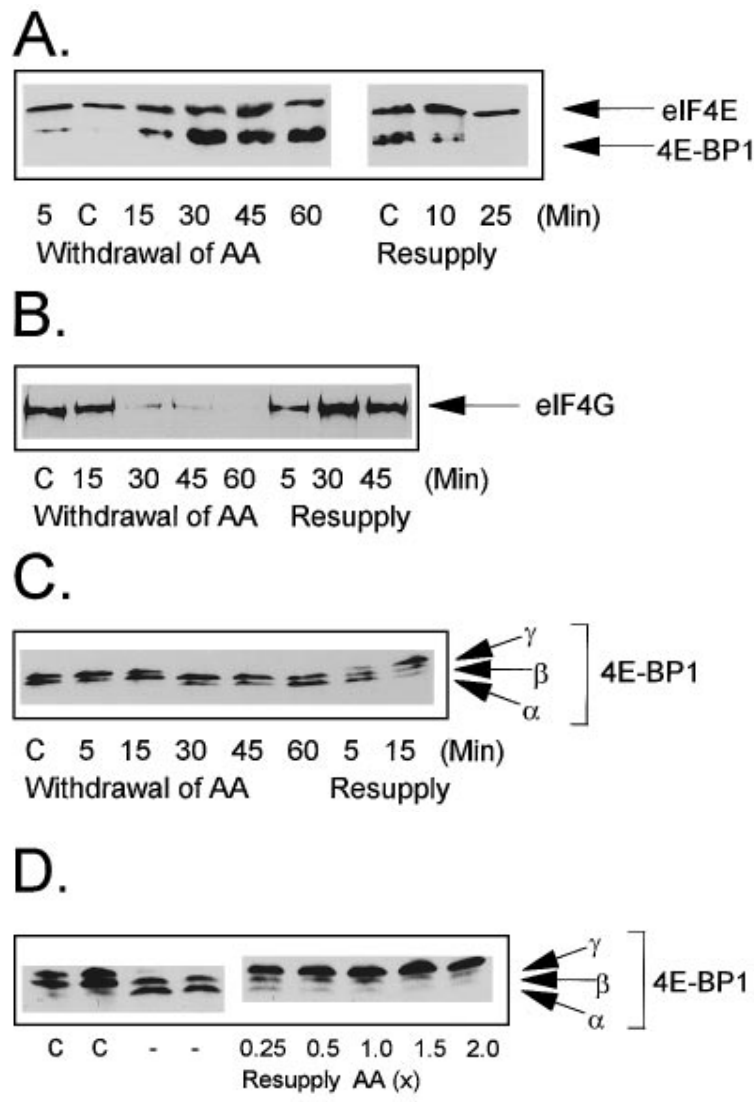

E.

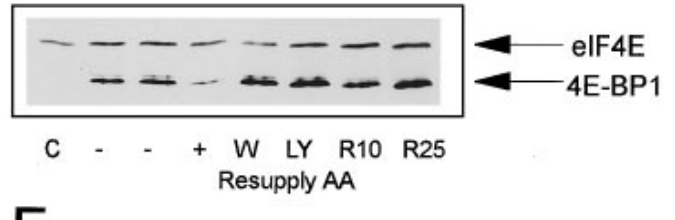

F.

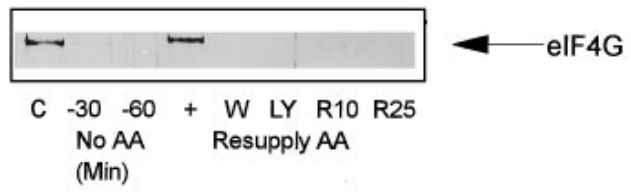

G.

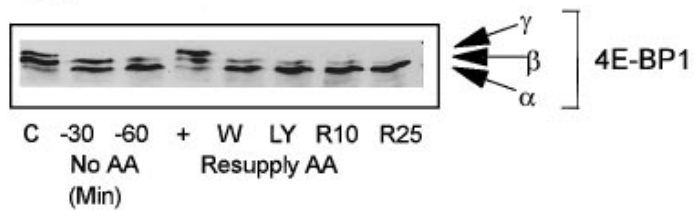

Figure 2 Amino acid supply modulates the association of elF4E with 4EBP1 and with elF4G

(A-C) CHO.K1 cells were untreated (C), or incubated without amino acids for the indicated times (Withdrawal of AA) or were incubated without amino acids for 45 min followed by resupply of amino acids for the times shown (Resupply). Extracts were then prepared: for $(\mathbf{A})$ and $(\mathbf{B})$ extracts were subjected to affinity chromatography on $\mathrm{m}^{7} \mathrm{GTP}-$ Sepharose followed by SDS/PAGE and immunoblotting using anti-elF4E and -4E-BP1 antisera (A) or anti-elF4G antiserum (B). For (C), extracts were subjected directly to SDS/PAGE followed by Western blotting with anti-4EBP1 antiserum. (D) CHO.K1 cells were either untreated (C) or incubated without amino acids for $45 \mathrm{~min}(-)$, followed by resupply of the standard amino acid mixture at the indicated

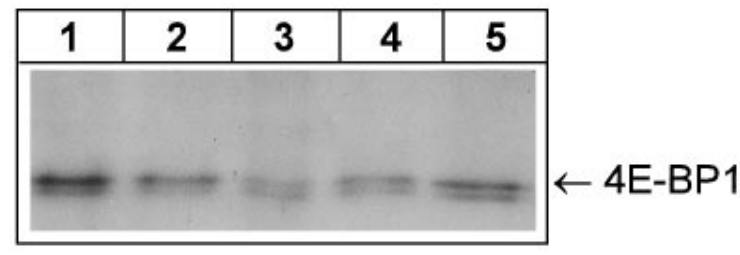

Figure 3 Amino acid supply regulates the phosphorylation of 4E-BP1

$\mathrm{CHO}$ cells were preincubated in the presence of $\left.{ }^{32} \mathrm{P}\right] \mathrm{P}_{\mathrm{i}}(0.5 \mathrm{mCl} / 10 \mathrm{~cm}$ plate $)$ in medium lacking phosphate. Cells were then further incubated in medium containing (30 min, lane 1) or lacking (15 min, lane 2; or 30 min, lanes 3-5) amino acids. After 30 min, amino acids were added back to the cells for 10 (lane 4) or 15 (lane 5) min. 4E-BP1 was isolated from the extracts by immunoprecipitation and analysed by SDS/PAGE (20\% acrylamide gel) followed by autoradiography. The migration position of 4E-BP1 (arrow) was identified by reference to appropriate marker proteins of known molecular mass.

phorylation of eIF4E by Mnk1 [41], it is likely that the fall in eIF4E phosphorylation was due to its increased binding to eIF4E in response to amino acid depletion, resulting in inhibition of its phosphorylation and consequent net dephosphorylation. Consistent with this, the ability of amino acid restoration to increase eIF4E phosphorylation was blocked either by rapamycin or by inhibitors of PI 3-kinase, all of which also block the ability of amino acids to induce dissociation of 4E-BP1 from eIF4E (Figure 4A; cf. Figure 2E).

Elongation factor eEF2 is also subject to phosphorylation, the phosphorylated form of the protein being inactive in translation $[42,43]$. As shown in Figure 4(B), amino acid depletion resulted in increased phosphorylation of eEF2. This effect was marked after 45 min of amino acid withdrawal and the factor was almost completely in its phosphorylated form after $60 \mathrm{~min}$.

\section{elF2 and elF2B}

In other types of mammalian cells amino acid depletion has been shown to cause increased phosphorylation of eIF $2 \alpha$ [44]. However, in CHO cells, amino acid depletion did not bring about a detectable change in eIF $2 \alpha$ phosphorylation, even after $1 \mathrm{~h}$ (Figure 4C) and, consistent with this, there was little if any decrease in the activity of eIF2B (after $45 \mathrm{~min}$ of amino acid withdrawal, eIF2B activity was $94.8 \pm 8.2 \%$ of control, $n=9$ ).

\section{Analysis of roles of individual amino acids}

Addition of any of the amino acids in our standard mixture alone (at the concentrations present in that mixture) did not affect p70 S6 kinase activity, the phosphorylation of 4E-BP1 or its binding to eIF4E, or the association of eIF4E with eIF4G (Figure 4 and results not shown). Given the very large number of possible

concentrations relative to the standard concentration $(=1.0)$ for 20 min. Analysis was as for (C). (E-G) CHO.K1 cells were untreated or deprived of amino acids (E, for $45 \mathrm{~min},-)$ for the times shown $(\mathbf{F}, \mathbf{G})$ followed, where indicated $(+)$, by incubation for 20 min in the presence of the full amino acid mixture with wortmannin (W, $100 \mathrm{nM})$, LY294002 (LY, $30 \mu \mathrm{M})$ or rapamycin ( $\mathrm{R}$, at 10 or $25 \mathrm{nM}$ as indicated). (These inhibitors were added when amino acids were withdrawn, and were therefore present for 45 min before amino acids were resupplied.) Analysis for $(\mathbf{E}-\mathbf{G})$ was as for $(\mathbf{A}-\mathbf{C})$, respectively. The positions of elF4E and 4E-BP1 are indicated in $(\mathbf{A})$ and $(\mathbf{E})$ : the major species of $4 \mathrm{E}-\mathrm{BP} 1$ associated with elF4E is $\alpha$ (least phosphorylated). The positions of the $\alpha, \beta$ and $\gamma$ species of 4E-BP1 are indicated in (C), (D) and $(\mathbf{G})$. elF4G is indicated in $(\mathbf{B})$ and $(\mathbf{F})$. 


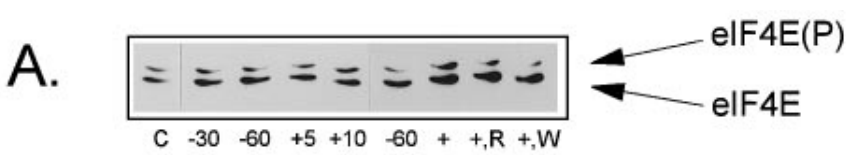

B.

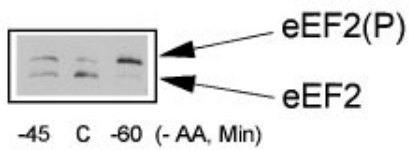

C.

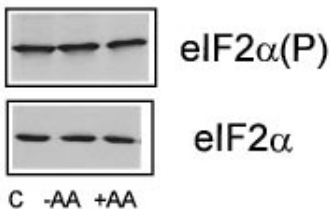

Figure 4 Amino acid supply modulates the phosphorylation of certain other translation factors

(A) $\mathrm{CHO}$.K1 cells were untreated (C) or incubated without amino acids for the times shown (min; $-30,-60$ ). In some cases, after 60 min of incubation without amino acids, amino acids were added (all lanes marked ' + ') and the incubation continued for 5 or 10 min $(+5,+10)$ or for $20 \mathrm{~min}(+)$. In some cases, rapamycin $(+\mathrm{R}, 25 \mathrm{nM})$ or wortmannin $(+\mathrm{W}, 100 \mathrm{nM})$ were added when amino acids were withdrawn, and were present when amino acids were resupplied. Extracts were then subjected to affinity chromatography on $\mathrm{m}^{7} \mathrm{GTP}-$ Sepharose followed by isoelectric focusing analysis and immunoblotting using anti-elF4E antiserum. The positions of the unphosphorylated and phosphorylated forms of elF4E are shown. (B) CHO.K1 cells were untreated (C) or incubated without amino acids for the times shown. Extracts were subjected to isoelectric focusing analysis followed by immunoblotting with anti-eEF2 antiserum. The positions of the unphosphorylated and phosphorylated forms of eEF2 are shown. (C) CHO.K1 cells were untreated $(C)$ or incubated without amino acids for $45 \min (-A A)$. Amino acids were then resupplied for $20 \mathrm{~min}(+\mathrm{AA})$. Extracts were subjected to SDS/PAGE and Western blotting using either an antiserum specifically recognizing the phosphorylated form of elF2 $\alpha$ [elF2 $\alpha(\mathrm{P})$, upper blot], or a monoclonal antibody recognizing elF2 $\alpha$ irrespective of its state of phosphorylation (lower blot)

permutations, we have not tested combinations of two or more amino acids. When added at higher concentrations (up to 5 times the standard concentration), leucine alone could activate p70 S6 kinase (to $78 \%$ of the control, the value for amino acid-depleted cells being $46 \%$, a mean of 2 experiments) and led to partial phosphorylation of 4E-BP1 (Figure 4). The fact that leucine alone is able to do this suggests that this phenomenon is not associated with the cell swelling linked to $\mathrm{Na}^{+}$ions, which leads to activation of p70 S6 kinase in liver cells [45], since leucine is not transported on a sodium-linked carrier in $\mathrm{CHO}$ cells [46]. Conversely, D-aspartate, which is not a precursor for protein synthesis but is transported on a sodium-linked carrier [46], did not cause activation of p70 S6 kinase (data not shown), also arguing against an effect mediated by cell swelling.

\section{DISCUSSION}

The data presented here demonstrate that amino acid availability regulates the activity of the signalling pathway, which leads to the activation of p70 S6 kinase. These data offer an explanation for the observation [47] that amino acid deficiency results in decreased phosphorylation of ribosomal protein S6 (which leads to activation of autophagy, increasing the supply of intracellular amino acids). Furthermore, they demonstrate that amino acid supply modulates several important regulatory translation factors through a variety of mechanisms. These include the following.

(1) The availability of eIF4E, which is involved in cap-dependent translation initiation and the modulation of several important regulatory steps in translation, and forms a complex with eIF4G and the helicase eIF4A (termed eIF4F [2,9,48]). By bringing about the dephosphorylation of 4E-BP1, and thus increasing its binding of eIF4E, amino acid deficiency results in dissociation of the eIF4F complex. This is expected to lead to decreased translation, especially of mRNAs whose 5'-untranslated regions are rich in secondary structure, which inhibits their translation, and which is believed to be unwound by eIF4A as part of eIF4F.

(2) The phosphorylation of eIF4E, which decreases in response to amino acid deprivation. Since phosphorylation of eIF4E enhances the affinity of eIF4E for mRNA [49] and may facilitate its incorporation into initiation complexes [50,51], this effect could contribute to the inactivation of mRNA translation too.

(3) The assembly of eIF4F. Amino acid resupply leads to formation of eIF4E-4G complexes, which is probably linked to the dissociation of eIF4E from 4E-BP1 and, perhaps, to the increased

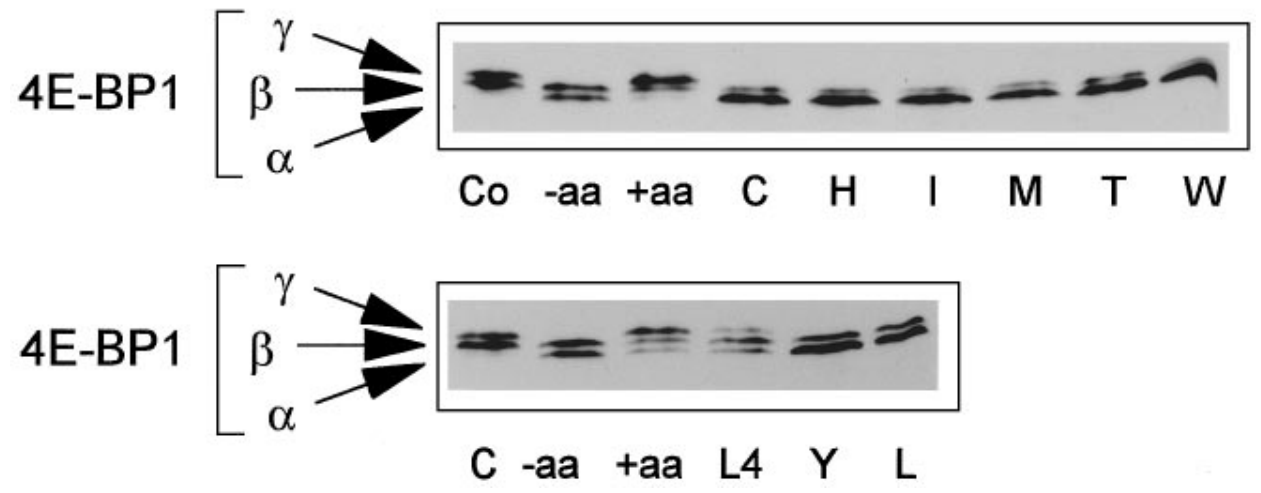

Figure 5 Effects of individual amino acids alone

CH0.K1 cells were untreated (Co) or incubated without amino acids ( - aa) for $45 \mathrm{~min}$. Where indicated, cells were then supplied with the full amino acid mixture $(+$ aa) or individual amino acids at the concentration found in the mixture; cysteine $(C)$, histidine $(H)$, isoleucine $(I), L$ (leucine, also used at $4 \mathrm{mM}, L 4)$, methionine $(M)$, threonine $(T)$, tryptophan $(W)$ or tyrosine $(Y)$, in each case for 20 min. Cell extracts were prepared and subjected to SDS/PAGE followed by Western blotting with anti-4E-BP1 antiserum. The positions of the $\alpha$, $\beta$ and $\gamma$ species of 4E-BP1 are indicated. 
phosphorylation of eIF4E, which are induced by resupplying amino acids.

(4) The phosphorylation of eEF2, which is increased by removal of amino acids. Since phosphorylated eEF2 is inactive in translation $[42,43]$, this effect would result in inhibition of elongation in parallel with the inhibition of initiation caused by the preceding two effects.

The data also suggest that amino acid supply regulates the translation of the $5^{\prime}$-TOP mRNAs. Although we have not examined this in our present study, there is now substantial evidence that the translation of these mRNAs is regulated through the rapamycin-sensitive signalling pathway that leads to p70 S6 kinase activation and phosphorylation of S6, which lies in the mRNA-binding site of the $40 \mathrm{~S}$ subunit ([13]; reviewed in [52]). These mRNAs encode proteins such as elongation factors and ribosomal proteins. It makes excellent physiological sense that the translation of such mRNAs should be shut off in response to amino acid deficiency. p70 S6 kinase is also involved in regulating cell-cycle progression $[10,53,54]$ and the results reported here point to a mechanism through which nutrient (amino acid) availability could modulate cell growth and division.

Resupplying amino acids results in activation of p70 S6 kinase and the reversal of the changes described above. The ability of rapamycin to block this is consistent with the key role of RAFT (rapamycin and FK506-binding protein-12 target)/mTOR in the activation of p70 S6 kinase in response to all known stimuli in mammalian cells [10]. The fact that these effects were also blocked by either of two structurally unrelated inhibitors of PI 3kinase, LY294002 and wortmannin, suggests that the regulation of this pathway by amino acids involves one or more members of the PI 3-kinase family of enzymes. It is currently unclear how amino acid supply could be linked to the regulation of PI 3kinase(s). Earlier work has suggested that PKB, a protein kinase that is regulated in a PI 3-kinase-dependent manner [20,55-58], may lie upstream of p70 S6 kinase [36,37]. However, in our experiments, amino acids had no effect on PKB activity under conditions where they markedly activated p70 S6 kinase. Thus, although amino acid-induced activation of p70 S6 kinase requires PI 3-kinase, it seems to be independent of activation of PKB, implying the operation of alternative upstream signalling pathways.

p70 S6 kinase has recently been reported to be a substrate for FRAP/mTOR [59] and for phosphoinositide-dependent kinase1 (PDK1) [60,61], a kinase that also phosphorylates and activates $\mathrm{PKB}$. The fact that rapamycin blocks the activation of $\mathrm{p} 70 \mathrm{~S} 6$ kinase by amino acids indicates that FRAP/mTOR is also involved in this effect (as it is for all known activators of p70 S6 kinase in mammals). The activity of PDK1 against PKB is constitutive, i.e. it is not enhanced, for example by insulin or by 3 -phosphoinositides $[60,62]$. It is therefore unlikely that direct regulation of this enzyme itself plays a role in the activation of p70 S6 kinase (although its ability to phosphorylate p70 S6 kinase may well be influenced by the phosphorylation of other sites in p70 S6 kinase [37]). We have not therefore measured its activity in this study.

In certain other mammalian cell-types, and in Saccharomyces cerevisiae, amino acid deficiency has been shown to cause increased phosphorylation of eIF $2 \alpha$ and/or inhibition of the guanine-nucleotide exchange factor eIF2B (reviewed in $[44,63]$ ), although this does not seem to be the case in the present experiments. This may reflect the way in which the experiments were performed. Earlier work, which showed increased eIF2 $\alpha$ phosphorylation, generally employed protocols that were likely to lead to the accumulation of uncharged tRNAs (i.e. temperature-sensitive amino acyl-tRNA synthetase mutants $[64,65]$, or amino acid analogues that inhibit these enzymes [63]), whereas this work involved removal of extracellular amino acids instead, which may not cause accumulation of uncharged tRNA on the time scale employed here. It is possible that uncharged tRNAs activate a mammalian homologue of the eIF $2 \alpha$ kinase GCN2, leading to increased eIF $2 \alpha$ phosphorylation, whereas removal of external amino acids does not.

Taken together with the earlier work on eIF2 and eIF2B, it seems that amino acids can regulate multiple translation factors through the operation of at least two types of regulatory event (the p70 S6 kinase or FRAP/mTOR pathway and the phosphorylation of eIF $2 \alpha$ ), although the relative contribution of different effects seems likely to vary depending, for example, on the conditions. Both may play roles in the overall regulation of translation (through the phosphorylation of eEF2 and eIF2 $\alpha$ ), while the rapamycin-sensitive regulation of p70 S6 kinase and of eIF4F is likely to be important in controlling the translation of specific mRNAs (e.g. 5'-TOP mRNAs and those with extensive secondary structure in their $5^{\prime}$-untranslated regions).

Since conducting our studies, Fox et al. [66] have reported that amino acids stimulate the phosphorylation of p70 S6 kinase in rat adipocytes and $\mathrm{Xu}$ et al. [67] have found that amino acids induce partial phosphorylation of 4E-BP1 in islets of Langerhans.

This work was supported by a Programme Grant from the Wellcome Trust (to C.G.P.). The initial observation that amino acid deficiency results in binding of 4E-BP1 to elF4E was made by R. Vries (University of Leiden, The Netherlands) while working in this laboratory. We thank L. Wang for valuable assistance with the p70 S6 kinase assays and Dr. J. McGivan (University of Bristol, Bristol, U.K.) for helpful comments and advice.

\section{REFERENCES}

Price, N. T. and Proud, C. G. (1994) Biochimie 76, 748-760

2 Pain, V. M. (1996) Eur. J. Biochem. 236, 747-771

3 Clemens, M. J. (1996) in Translational Control (Hershey, J. W. B., Mathews, M. B. and Sonenberg, N., eds.), pp. 139-172, Cold Spring Harbor Press, Cold Spring Harbor

4 Hinnebusch, A. G. (1994) Trends Biochem. Sci. 19, 409-414

5 Hinnebusch, A. G. (1997) J. Biol. Chem. 272, 21661-21664

6 Santoyo, J., Alcalde, J., Mendez, R., Pulido, D. and deHaro, C. (1997) J. Biol. Chem. 272, 12544-12550

7 Rhoads, R. E. (1993) J. Biol. Chem. 268, 3017-3020

8 Redpath, N. T. and Proud, C. G. (1994) Biochim. Biophys. Acta 1220, 147-162

9 Lawrence, J. C. and Abraham, R. T. (1997) Trends Biochem. Sci. 22, 345-349

10 Proud, C. G. (1996) Trends Biochem. Sci. 21, 181-185

11 Jefferies, H. B. J., Reinhard, G., Kozma, S. C. and Thomas, G. (1994) Proc. Natl. Acad. Sci. U.S.A. 91, 4441-4445

12 Terada, N., Patel, H. R., Takase, K., Kohno, K., Nairn, A. C. and Gelfand, E. W. (1994) Proc. Natl. Acad. Sci. U.S.A. 91, 11477-11481

13 Jefferies, H. B. J., Fumagalli, S., Dennis, P. B., Reinhard, C., Pearson, R. B. and Thomas, G. (1997) EMBO J. 16, 3693-3704

14 Redpath, N. T., Foulstone, E. J. and Proud, C. G. (1996) EMBO J. 15, 2291-2297

15 Flynn, A. and Proud, C. G. (1996) Eur. J. Biochem. 236, 40-47

16 DeGracia, D. J., Sullivan, J. M., Neumar, R. W., Alousi, S. S., Hikade, K. R., Pittman, J. E., White, B. C., Rafols, J. A. and Krause, G. S. (1997) J. Cereb. Blood Flow Metab. 17, 1291-1302

17 Walker, K. S., Deak, M., Paterson, A., Hudson, K., Cohen, P. and Alessi, D. R. (1998) Biochem. J. 331, 299-308

18 Dickens, M., Chin, J. E., Roth, R. A., Ellis, L., Denton, R. M. and Tavaré, J. M. (1992) Biochem. J. 287, 201-209

19 Moule, S. K., Edgell, N. J., Welsh, G. I., Diggle, T. A., Foulstone, E. J., Heesom, K. J., Proud, C. G. and Denton, R. M. (1995) Biochem. J. 311, 595-601

20 Cross, D. A. E., Alessi, D. R., Cohen, P., Andjelkovich, M. and Hemmings, B. A. (1995) Nature (London) 378, 785-789

21 Cuenda, A., Rouse, J., Doza, Y. N., Meier, R., Cohen, P., Gallagher, T. F., Young, P. R. and Lee, J. C. (1995) FEBS Lett. 364, 229-233

22 Minden, A., Lin, A., Claret, F.-X., Abo, A. and Karin, M. (1995) Cell 81, 1147-1157

23 Diggle, T. A., Moule, S. K., Avison, M. B., Flynn, A., Foulstone, E. J., Proud, C. G. and Denton, R. M. (1996) Biochem. J. 316, 447-453

24 Flynn, A. and Proud, C. G. (1996) FEBS Lett. 389, 162-166 
25 Flynn, A. and Proud, C. G. (1995) J. Biol. Chem. 270, 21684-21688

26 Redpath, N. T. (1992) Anal. Biochem. 202, 340-343

27 Reference deleted.

28 Chung, J., Grammer, T. C., Lemon, K. P., Kazlauskas, A. and Blenis, J. (1994) Nature (London) 370, 71-75

29 Dahl, J., Freund, R., Blenis, J. and Benjamin, T. L. (1996) Mol. Cell. Biol. 16 2728-2735

30 Wilson, M., Burt, A. R., Milligan, G. and Anderson, N. G. (1996) J. Biol. Chem. 271, $8537-8540$

31 Petritsch, C., Woscholski, R., Edelmann, H. M. L., Parker, P. J. and Ballou, L. M. (1995) Eur. J. Biochem. 230, 431-438

32 Cheatham, B., Vlahos, C. J., Cheatham, L., Wang, L., Blenis, J. and Kahn, C. R. (1994) Mol. Cell. Biol. 14, 4902-4911

33 Weng, Q. P., Andrabi, K., Klippel, A., Kozlowski, M. T., Williams, L. T. and Avruch, J. (1995) Proc. Natl. Acad. Sci. U.S.A. 92, 5744-5748

34 Weng, Q.-P., Andrabi, K., Kozlowski, M. T., Grove, J. R. and Avruch, J. (1995) Mol. Cell. Biol. 15, 2333-2340

35 Wang, X., Flynn, A., Waskiewicz, A. J., Webb, B. L. J., Vries, R. G. J., Baines, I. A., Cooper, J. and Proud, C. G. (1998) J. Biol. Chem. 273, 9373-9377

36 Burgering, B. M. T. and Coffer, P. J. (1995) Nature (London) 376, 599-602

37 Peterson, R. T. and Schreiber, S. L. (1998) Curr. Biol. 8, R248-R250

38 Von Manteuffel, S. R., Dennis, P. B., Pullen, N., Gingras, A.-C., Sonenberg, N. and Thomas, G. (1997) Mol. Cell. Biol. 17, 5426-5436

39 Haghighat, A., Mader, S., Pause, A. and Sonenberg, N. (1995) EMBO J. 14 5701-5709

40 Mader, S., Lee, H., Pause, A. and Sonenberg, N. (1995) Mol. Cell. Biol. 15, 4990-4997

41 Vries, R. G. J., Flynn, A., Patel, J. C., Wang, X., Denton, R. M. and Proud, C. G. (1998) J. Biol. Chem. 272, 32779-32784

42 Carlberg, U., Nilsson, A. and Nygard, 0. (1990) Eur. J. Biochem. 191, 639-645

43 Redpath, N. T., Price, N. T., Severinov, K. V. and Proud, C. G. (1993) Eur. J. Biochem. 213, 689-699

44 Proud, C. G. (1992) Curr. Top. Cell Regul. 32, 243-369

45 Krause, U., Rider, M. H. and Hue, L. (1996) J. Biol. Chem. 271, 16668-16673

46 McGivan, J. D. (1994) Biochem. J. 299, 321-334

47 Blommaart, E. F. C., Luiken, J. J. F. P., Blommaart, P. J. E., Vanwoerkom, G. M. and Meijer, A. J. (1995) J. Biol. Chem. 270, 2320-2326

Received 5 February 1998/27 May 1998; accepted 23 June 1998
48 Morley, S. J., Curtis, P. S. and Pain, V. M. (1997) RNA 3, 1085-1104

49 Minich, W. B., Balasta, M. L., Goss, D. J. and Rhoads, R. E. (1994) Proc. Natl. Acad. Sci. U.S.A. 91, 7668-7672

50 Sonenberg, N. (1996) in Translational Control (Hershey, J. W. B., Mathews, M. B. and Sonenberg, N., eds.), pp. 245-269, Cold Spring Harbor Press, Cold Spring Harbor

51 Flynn, A. and Proud, C. G. (1996) Cancer Surv. 27, 293-310

52 Jefferies, H. B. J. and Thomas, G. (1996) in Translational Control (Hershey, J. W. B., Mathews, M. B. and Sonenberg, N., eds.), pp. 389-409, Cold Spring Harbor Press, Cold Spring Harbor

53 Reinhard, C., Fernandez, A., Lamb, N. J. C. and Thomas, G. (1994) EMBO J. 13, 1557-1565

54 Lane, H. A., Fernandez, A., Lamb, N. J. C. and Thomas, G. (1993) Nature (London) 363, 170-172

55 Franke, T. F., Kaplan, D. R., Cantley, L. C. and Toker, A. (1997) Science 275 $665-668$

56 Klippel, A., Kavanaugh, W. M., Pot, D. and Williams, L. T. (1997) Mol. Cell. Biol. 17, 338-344

57 Alessi, D. R., Andjelkovic, M., Caudwell, B., Cron, P., Morrice, N., Cohen, P. and Hemmings, B. (1996) EMBO J. 15, 6541-6551

58 Cross, D. A. E., Watt, P. W., Shaw, M., van der Kaay, J., Downes, C. P., Holder, J. C. and Cohen, P. (1997) FEBS Lett. 406, 211-215

59 Burnett, P. E., Barrow, R. K., Cohen, N. A., Snyder, S. H. and Sabatini, D. M. (1998) Proc. Natl. Acad. Sci. U.S.A. 95, 1432-1437

60 Alessi, D. R., Kozlowski, M. T., Weng, Q.-P., Morrice, N. and Avruch, J. (1998) Curr. Biol. 8, 69-81

61 Pullen, N., Dennis, P. B., Andjelkovic, M., Dufner, A., Kozma, S. C., Hemmings, B. A. and Thomas, G. (1998) Science 279, 707-710

62 Alessi, D. R., Deak, M., Casamayor, A., Caudwell, F. B., Morrice, N. and Norman, D. G. (1998) Curr. Biol. 7, 776-789

63 Kimball, S. R., Antonetti, D. A., Brawley, R. M. and Jefferson, L. S. (1991) J. Biol. Chem. 266, 1969-1976

64 Clemens, M. J., Galpine, A., Austin, S. A., Panniers, R., Henshaw, E. C., Duncan, R., Hershey, J. W. and Pollard, J. W. (1987) J. Biol. Chem. 262, 767-771

65 Pollard, J. W., Galpine, A. R. and Clemens, M. J. (1989) Eur. J. Biochem. 182, 1-9

66 Fox, H. L., Kimball, S. R., Jefferson, L. S. and Lynch, C. J. (1998) Am. J. Physiol. 43, C206-C213

67 Xu, G., Marshall, C. A., Lin, T.-A., Kwon, G., Munivenkatappa, R. B., Hill, J. R., Lawrence, J. C. and McDaniel, M. L. (1998) J. Biol. Chem. 273, 4485-4491 